\title{
ADSORTIVIDADE DO HERBICIDA “ZETA" EM SOLOS DE VARIADAS TEXTURAS ${ }^{1}$
}

\author{
A. MOREIRA ${ }^{2,5}$; S. C. de SIQUEIRA ${ }^{3,6}$; A.A. da SILVA 4 \\ 2 - Depto. de Ciencla do Solo-ESALQ/USP, C.P. 9, CEP 13.418-060, Piracicaba, SP. \\ 3 - Depto. de Qutmica-UET, CEP 77.410-000, Gurupi, TO. \\ 4- Depto. de Fitotecnia-UFV, C.P. 37, CEP 36.570-000, Vifosa, MG. \\ 5 - Bolsista da CAPES. \\ 6 - Bolsista do CNPq.
}

RESUMO: Com o objetivo de estimar a dose do herbicida "Zeta" que inibe $50 \%\left(I_{50}\right)$ do crescimento de plantas bioindicadoras em solos com diferentes texturas e teores de matéria organica, podendo estes ter uma infiuencia marcante sobre a bioatividade do herbicida testado, utilizou-se o delineamento experimental inteiramente casualizado com 7 tratamentos $(0,50,100,150,200,250$ e $300 \mathrm{~g}$ i.a./ha) e 4 repetiçōes, sendo os tratamentos dispostos em 5 tipos de texturas de solo. Os parametros avaliados foram: biomassa fresca total, biomassa seca da parte aérea e biomassa seca do sistema radicular das plantas de sorgo. De acordo com os resultados obtidos pode-se concluir que em solos com textura tendendo à arenosa o herbicida apresenta uma grande mobilidade vertical, e que altos teores de $A^{3+}$ no solo podem mascarar, de certa forma, a atuação do herbicida na planta. Em linhas gerais, o experimento permitiu inferir que quanto maior os teores de argilas ativas e de matéria orgánica presentes no solo, maior a dose do herbicida requerida para um dado controle percentual de plantas daninhas.

Descritores: alumínio, argila, bioatividade, biomassa fresca, biomassa seca, matéria orgánica

\section{“ZETA" HERBICIDE ADSORTIVITY IN SOILS OF VARIED TEXTURES}

ABSTRACT: To estimate the herbicide rate which inhibits $50 \%\left(\mathrm{I}_{50}\right)$ of the growth of bioindicator plants in soils of different textures and organic matter levels, which could interfere on the bioactivity of the tested herbicide, a completely randomized experiment was carried out with seven treatments $(0,50,100,150,200,250$ and $300 \mathrm{~g}$ a.i./ ha) and four replications, in five kinds of soil textures. The analyzed parameters were: total fresh biomass, dry shoot biomass and dry root biomass of the sorghum plants. According to the results, it can be concluded that in sandy soils the herbicide shows a great vertical mobility, and that high levels of $\mathrm{Al}^{3+}$ in the soil can minimize the herbicide effect on plants. The experiment also has shown that the higher the level of active clays and of organic matter in the soil, the higher the rate of herbicide required for a given weed control level.

Key words: aluminum, clay, bioactivity, fresh biomass, dry biomass, organic matter

\section{INTRODUÇÃO}

O conhecimento dos fatores que influenciam a atividade e estabilidade dos herbicidas no solo $\epsilon$ fundamental pois, através dele, poderemos explicar o sucesso ou o fracasso desses produtos no controle das plantas daninhas, a tolerância das culturas e a persistência dos mesmos em diferentes condições ambientais (ANDERSON, 1983). Sob o ponto de vista prático, $\epsilon$ importante conhecer, no solo, a fração do produto que se encontra biologicamente ativa, ou seja, a atividade de um produto em um determinado tempo e em uma determinada faixa de solo. A atividade de um herbicida no solo é influenciada pelos seguintes fatores: adsorção de sua moléculas pelos colóides do solo, perda dos mesmos por volatilização e/ou lixiviação, degradação microbiana, degradação química, fotólise, absorção e degradação pelas plantas (ANDERSON, 1983). Estes fatores, juntamente com a germinação e o estabelecimento das plantas daninhas, são fortemente influenciados pelo grau de umidade do solo.

O SAN $582 \mathrm{H}$ ou Zeta (Quadro 1) é um herbicida experimental utilizado preferencialmente em pré-emergência. Possui um largo espectro de ação, combinando controle de gramíneas anuais com controle ou supressão da germinação, crescimento e desenvolvimento de muitas plantas daninhas de folhas largas e ciperáceas (AHRENS,

1 - Trabalho apresentado no XXV Congresso Brasileiro de Ciência do Solo, Viçosa, MG.

Sel agric., Piracicaba, 52(3):502-508, set./dez. 1995 
1994). Este produto, $€$ o único herbicida até o momento pertencente a grupo tiofeno-base cloroacetamida (AHRENS, 1994), atuando na inibição da síntese do ácido giberélico em sementes em germinação, reduzindo drasticamente a divisão celular $\mathrm{e} 0$ crescimento das plântulas, levando-as à morte imediatamente após a emergência da superficie do solo (SCALLA, 1991). O herbicida até o momento mostrou-se seletivo para as culturas do milho e da soja. Estudos de tolerância prosseguem em outras espécies cultivadas. 0 produto pode ser aplicado em pre-plantio, preplantio incorporado, pre-emergencia ou em posemergência precoce das culturas. 0 ingrediente ativo é usado na dose de 0,85 a $1,64 \mathrm{~kg}$ i.a./ha, dependendo da textura e do teor de matéria orgânica do solo (AHRENS,1994). Segundo o fabricante, o herbicida Zeta não $\epsilon$ persistente no solo. É degradado principalmente por microorganismos do solo. Possui um adequado efeito residual que confere controle durante o ciclo da cultura sem afetar culturas subsequentes.

0 presente trabalho teve por objetivo estimar a dose do herbicida que inibe $50 \%\left(\mathrm{~L}_{50}\right)$ do crescimento de plantas bioindicadoras, em solos com diferentes texturas e teores de matéria orgánica.

A hipótese aventada $\epsilon$ que as caracteristicas físicas e químicas do solo exercem influência marcante sobre a bioatividade do herbicida testado. Para tanto, foram montados bioensaios baseados na inibição do crescimento do caulículo e da radícula das plantas-testes.

\section{MATERIAL E MÉTODOS}

O experimento foi conduzido em casa de vegetação do Departamento de Fitotecnia da Universidade Federal de Viçosa (UFV), localizado no município de Viçosa, Minas Gerais.

Os solos utilizados foram coletados no "banco de solos da UPV", peneirados em peneira com malha de $4 \mathrm{~mm}$ para destorroamento e uniformização. Após secagem ao ar e a sombra, amostras foram destinadas ao laboratório, a fim de que fossem determinadas suas características físicas e químicas (TABELA 1). $O$ substrato areia, foi lavado em água corrente e tratado com ácido muriático para eliminação de resíduos orgânicos.

Como recipiente utilizou-se vasos plásticos com volume de $400 \mathrm{~cm}^{3}$, revestidos internamente com sacos plásticos de $0,05 \mathrm{~mm}$ de espessura para evitar a drenagem da solução do lixiviado contendo moleculas do ingrediente ativo do herbicida, como tambem, restringir as perdas de umidade apenas à evapotranspiração. Foram aplicadas soluções de Hoagland modificadas, tres vezes por semana até - término do experimento. Utilizou como plantateste ou bioindicadora, o sorgo (Sorghum bicolor L.) com uma densidade de 6 sementes por vaso, semeadas em solo seco.

O herbicida foi aplicado à superfície dos vasos contendo solo seco, com pulverizador costal pressurizado com CO, munido de 1 bico tipo leque $80.03 \mathrm{com}$ pressão dé $2,5 \mathrm{~kg} / \mathrm{cm}^{2}$, gastando-se o equivalente a 200 litros da solução por hectare. Após o plantio e aplicação do herbicida, efetuouse a irrigação dos vasos até atingir $90 \%$ da capacidade de campo, fator este determinado pela curva característica de umidade. As irrigaçóes foram feitas três vezes ao dia, sempre a superfície dos recipientes, atraves de uma precipitação simulada de $90 \mathrm{~mm} / \mathrm{h} o r a$, por meio de um simulador de chuvas para vasos para manter $a$ umidade dos vasos constante.

O delineamento experimental foi o inteiramente casualizados com 7 tratamentos (0; 50; 100; 150; 200; 250 e $300 \mathrm{~g}$ i.a./ha) e 4 repetiçoes sendo que os tratamentos foram dispostos em 5 tipos de solos com texturas diferentes (TABELA 1).

As plantas foram colhidas 21 dias apos o início da irrigação, lavadas em água corrente sobre peneira de malha de $2 \mathrm{~mm}$, em seguida, estendidas sobre papel toalha de textura fina $e$, suavemente enxutas, para obtenção da matéria fresca. Posteriormente a parte área foi cindida do sistema radicular, tendo sido, ambos, encerrados em saquinhos de papel em estufa $65^{\circ} \mathrm{C}$ até peso constante e novamente submetidos a pesagem da biomassa seca. Os parâmetros avaliados foram: biomassa fresca total, biomassa seca da parte aerea e biomassa do sistema radicular, os resultados foram submetidos a análise de regressão polinomial, utilizando o programa estatístico SANEST (SARRIÉs et al., 1992).

\section{RESULTADOS E DISCUSSÃO}

No presente experimento, o herbicida Zeta foi aplicado à superfície dos vasos contendo solo seco, em seguida, procedeu-se irrigação dos vasos contendo solo seco até $90 \%$ da capacidade de campo. ALMEIDA \& RODRIGUES (1988) afirmam, que para os herbicidas derivados da amida 
serem eficientes, $e$ imprescindível que sejam pulverizados sobre o solo úmido ou que ocorra uma chuva de 10 a $15 \mathrm{~mm}$, logo após a sua aplicação.

O I $\mathrm{I}_{\mathbf{5 0}}$ pertinente a biomassa fresca total em plantas de sorgo (Sorghum bicolor L.) no solo de textura muito argilosa foi de $152 \mathrm{~g}$ i.a./ha (TABELA 2). Fato esse, que contraria uma certa expectativa inicial de que o $l_{50}$ fosse bem maior $\mathrm{em}$ decorrência do elevado teor de argila e de matéria orgânica desse solo o que implicaria em maior adsorção das moléculas do herbicida aos colóides minerais e orgânicos neles presentes, por meio de pontes de hidrogênio. Uma maior adsorção, por sua vez, reduz a quantidade de ingrediente ativo livre na solução do solo, por indisponibilidade do mesmo para absorção pelas plantas, dessa forma, exigindo uma maior dose para inibir o incremento de biomassa fresca em $50 \%$. É de supor que os fatores que condicionaram um valor baixo para $l_{50}$ nesse solo de textura muito argilosa, tenha sido o elevado teor de alumínio tóxico (TABELA 1). Segundo MUZILLI et al. (1991), o desenvolvimento do sorgo em ambiente ácido é prejudicado indiretamente, pela redução na disponibilidade da maioria dos nutrientes e diretamente pela alta concentração de íns $\mathrm{Al}^{+3}$ que, uma vez absorvidos, saturam as células livres do córtex, inibindo o crescimento do sistema radicular (MUZILLI et al., 1991). As raízes afetadas com alumínio, apresentaram com coloração parda, grossas e hipotrofiadas. As raízes secundárias ficaram entumecidas, provocando a inibição do desenvolvimento de suas extremidades reduzindo a absorção de água, comprometendo negativamente o crescimento e desenvolvimento da parte aérea, minorando, dessa forma, o incremento de biomassa fresca total. Para WEBER \& MILLER (1989), o alumínio é um fator importante que pode interagir com o herbicida em diferentes condições, determinando a sua taxa de degradação e, conseqüentemente, sua persistência no solo. Os $\mathbf{I}_{50}$ concernentes ao incremento de biomassa seca radicular e da biomassa seca da parte aérea se comportam em conformidade com a premissa anterior (TABELAS 3 e 4).

TABELA 1 - Resultados das análises físico-químicas dos solos utilizados no experimento em casa de vegetação.

\begin{tabular}{|c|c|c|c|c|c|}
\hline & M. Argiloso & Argiloso & Fr-Arg-Arenoso & Areia Franca & Areia Lav. \\
\hline Argila (\%) & 73,00 & 56,00 & 27,00 & 13,00 & 3,00 \\
\hline $\mathrm{pH}$ em $\mathrm{H}_{2} \mathrm{O}$ & 4,83 & 4,83 & 5,40 & 5,80 & 6,30 \\
\hline CTC $(\mathrm{cmol} / \mathrm{kg})$ & 0,78 & 1,99 & 1,63 & 0,31 & - \\
\hline M.O. (\%) & 3,93 & 5,67 & 2,17 & 1,27 & 0,00 \\
\hline $\mathrm{Al}^{3+}\left(\mathrm{cmol}_{c} / \mathrm{kg}\right)$ & 1,00 & 0,63 & 0,27 & 0,20 & - \\
\hline
\end{tabular}

TABELA 2 - Equações de regressão, coeficiente de determinação $\left(R^{2}\right)$ e $0 I_{s 0}$ da biomassa fresca total ( $g$ / vaso) para os diferentes tipos de textura estudados.

\begin{tabular}{llcr}
\hline \multicolumn{1}{c}{ Textura } & \multicolumn{1}{c}{ Equação de regressão } & $R^{2}$ & $I_{\text {so }}$ (g i.a./ha) \\
\hline Muito Argiloso & $\mathrm{Y}=4,22135-0,01259 \mathrm{X}-0,0000082 \mathrm{X}^{2}$ & $0,69^{*}$ & 152,00 \\
Argiloso & $\mathrm{Y}=14,46052+0,05128 \mathrm{X}-0,0000473 \mathrm{X}^{2}$ & $0,92^{*}$ & 132,00 \\
Fr-Arg-Arenoso & $\mathrm{Y}=16,32312+0,0157518 \mathrm{X}-0,0000961 \mathrm{X}^{2}$ & $0,95^{\circ}$ & 225,00 \\
Areia Franca & $\mathrm{Y}=4,74339-0,0163893 \mathrm{X}$ & $0,96^{\circ}$ & 144,00 \\
Areia Lavada & $\mathrm{Y}=12,88691+0,0292014 \mathrm{X}-0,0001272 \mathrm{X}^{2}$ & $0,90^{\circ}$ & 354,00 \\
\hline \hline
\end{tabular}

* Significativo ao nível de $5 \%$ de probabilidade.

O I 50 estimados para o solo de textura argilosa (TABELA 2, 3 e 4) relativos aos três parâmetros avaliados, se mostraram ligeiramente inferiores aos do solo de textura muito argilosa, podendo, o fato ser atribuído ao seu menor percentual de argilas ativas (TABELA 1), implicando em uma menor adsorção do herbicida aplicado, pelos coloides minerais do solo, requerendo menor dose do herbicida para inibir $50 \%$ do crescimento das plantas testes. Os acetamidas também podem ser inativados por adsorção em solos que apresentem altos teores de 
TABELA 3 - Equação de regressão, coeficiente de determinação $\left(R^{2}\right)$ e o $\mathfrak{l}_{50}$ da biomassa seca da parte aérea (g/vaso) para os diferentes tipos de textura estudados.

\begin{tabular}{|c|c|c|c|}
\hline Textura & Equação de regressão & $\mathbf{R}^{2}$ & $I_{s 0}(g$ i.a./ha) \\
\hline Muito Argiloso & $Y=0,48708-0,0002815 X$ & $0,52^{*}$ & 192,00 \\
\hline Argiloso & $Y=0,940000-0,0051065 X+0,00008010 X^{2}$ & $0,94^{*}$ & 111,00 \\
\hline Fr-Arg-Arenoso & $Y=0,969375+0,0029298 X+0,00001540 X^{2}$ & $0,84^{*}$ & 285,00 \\
\hline Areia Franca & $Y=0,368512-0,0002286 X-0,00000326 X^{2}$ & $0,81^{*}$ & 209,00 \\
\hline Areia Lavada & $Y=1,070095+0,0007629 X-0,00000586 X^{2}$ & $0,53^{*}$ & 371,00 \\
\hline
\end{tabular}

* Significativo ao nível de $5 \%$ de probabilidade.

TABELA 4 - Equação de regressão, coeficiente de determinação $\left(R^{2}\right)$ e $\circ \mathfrak{l}_{50}$ da biomassa seca do sistema radicular ( $\mathrm{g} / \mathrm{vaso}$ ) para os diferentes tipos de textura estudados.

\begin{tabular}{|c|c|c|c|}
\hline Textura & Equação de regressão & $\mathbf{R}^{2}$ & $I_{\text {so }}$ (g i.a./ha) \\
\hline Muito Argiloso & $Y=0,450625-0,0011286 X$ & $0,62^{*}$ & 195,00 \\
\hline Argiloso & $Y=0,673021-0,0040491 X+0,00000801 X^{2}$ & $0,92^{*}$ & 103,00 \\
\hline Fr-Arg-Arenoso & $Y=1,234167-0,0044560 X+0,00000407 X^{2}$ & $0,80^{*}$ & 75,00 \\
\hline Areia Franca & $Y=0,389583-0,0001589 X-0,00000373 X^{2}$ & $0,82^{*}$ & 212,00 \\
\hline Areia Lavada & $Y=0,422012+0,0030642 X-0,00000980 X^{2}$ & $0,76^{\circ}$ & 375,00 \\
\hline
\end{tabular}

* Significativo ao nível de $5 \%$ de probabilidade.

Quadro 1 - Descrição técnica do herbicida testado.

Fórmula Estrutural:<smiles>COCC(C)N(C(=O)CCl)C1C(C)CSC1C</smiles>

Nome Comum: Zeta ou SAN 582H

Nome Técnico: Dimethenamid

Nome Químico: (1RS, aRS)-2-cloro-N-(2,4-dimetil-3-tienil)-N-(2-metoxi-1-metiletil)-acetamida

Fórmula Molecular: $\mathrm{C}_{12} \mathrm{H}_{18} \mathrm{ClNO}_{2} \mathrm{~S}$

Peso Molecular: 275,79

Densidade: $1,185 \mathrm{~g} / \mathrm{ml}$ a $25^{\circ} \mathrm{C}$

Pressão de Vapor: $2,7 \times 10^{-4} \mathrm{~mm}$ de $\mathrm{Hg}$ a $25^{\circ} \mathrm{C}$

Ponto de Ebulição: $>250^{\circ} \mathrm{C}$ a $760 \mathrm{~mm} \mathrm{Hg}, 123^{\circ} \mathrm{C}$ a $0,1 \mathrm{~mm} \mathrm{Hg}$ 
argila e/ou matéria orgânica (ESHEL, 1968; PUTNAN \& RICE, 1979 e PETER \& WEBER, 1985). Trabalhos experimentais tem demonstrado que a fração orgânica é muito importante na adsorção dos herbicidas, em razão de sua elevada capacidade de troca catiônica da superfície específica da argila e da presença de grupos funcionais carboxílicos, fenólicos e amínicos, existente na superfície dos colóides (OBRIGAWITH et al., 1981).

O solo franco-argilo-arenoso apresentou seus $I_{50}$ expressivamente superior ao dos solos anteriores (TABELAS 2, 3 e 4). Tratando de um solo de textura média com teor intermediário de matéria orgânica em relação ao demais solos (TABELA 1), presume-se que tenha havido menor adsorção das moléculas do herbicida pelos colóides minerais e orgânicos desse solo, apresentando, por consequuência, maior concentração na solução do solo. Fato esse, que limitaria a estimativa dos seus $I_{50}$ a valores bem abaixo dos $\underline{b}_{50}$ dos solos de textura muito argilosa e argilosa, com teores elevados de matéria orgânica. Tal fato não foi observado, supostamente, em decorrência da lixiviação vertical do produto ao longo do perfil do solo e seu acúmulo no fundo dos vasos, com isso, se afastando da zona de absorção radicular, exigindo, pois, dosagens maiores para inibir $50 \%$ do crescimento das plantas de sorgo. Esta suposição está de acordo com BALDWIN et al. (1985), tendo evidenciado que quando o herbicida prometrine foi aplicado $\mathrm{em}$ solo seco e simulou-se chuva, as perdas do herbicida foram de $5 \%$ ou menos, da quantidade aplicada. As perdas foram muito superiores nas parcelas nas quais o solo foi molhado, no momento da aplicação.

No solo de análise textural areia franca, os $I_{50}$ calculados (TABELAS 2, 3 e 4), foram ligeiramente inferiores aos do solo argilo-franco arenoso. Apesar de se esperar uma menor adsorção das moleculas do herbicida pelos col6ides minerais e orgânicos desse solo, em função de um baixo percentual de argila e matéria orgânica, condição essa que possibilitou uma maior disponibilidade do ingrediente ativo livre na solução do solo, exigindo menor dose para inibir 50\% do crescimento das plantas indicadoras. Infere-se que tenha havido menor lixiviação do produto em relação ao solo franco-argilo-arenoso. A temperatura diurna na casa de vegetação permaneceu ligeiramente acima dos $40^{\circ} \mathrm{C}$ durante todo transcurso do experimento. PUTNAN \& RICE (1979), comparam aplicações de acetamidas em pré-plantio incorporado e em pré emergência à superfície do solo. Verificaram que, sob condições de campo, a máxima injúria ocorreu quando as temperaturas, durante a germinação, foram baixas e a precipitação pluvial mínima ou quando a temperatura aproximou-se ou foi superior a $27^{\circ} \mathrm{C}$ e o solo permaneceu saturado.

A elevada atividade do herbicida Zeta na areia franca, pode ser explicada segundo DAO \& LAVY (1988), pelo fato das moléculas da água competirem com às do herbicida por sítios de adsorção no solo. Em estando o solo com baixo grau de umidade, o número de molécula de água competindo pelos sítios ativos de adsorção é relativamente pequeno e as moléculas do herbicida podem favoravelmente ser adsorvidas pelos colóides do solo. Sob níveis elevados de umidade, moléculas livres no solo, reduzem a adsorção das moléculas orgânicas, tais quais, as do herbicida testado. Assim sendo, apesar das condições de umidade do solo terem favorecido a rápida germinação das sementes e o crescimento radicular, o número de moléculas do Zeta adsorvidas foi pequeno. Como as condições em que foram realizados este experimento não permitiram a lixiviação do herbicida Zeta, e a sua concentração na solução do solo se manteve elevada, facultando uma maior eficiência, o que resultou em menores $\mathbf{I}_{50}$ para 0 solo de textura areia-franca.

$\mathrm{Na}$ areia lavada (textura areia), isenta de resíduos orgânicos, é de se pressupor adsorção praticamente inexistente. Os $\mathrm{I}_{50}$ obtidos para areia lavada (TABELAS 2, 3 e 4) concernentes aos três parâmetros avaliados, foram os mais elevados em comparação com os solos testados, denotando uma maior mobilidade do produto aplicado ao longo do perfil do substrato, se afastando efetivamente da zona de absorção radicular. Esta teoria é reforçada pelos trabalhos de PUTNAN \& RICE (1979), os quais, mostram que o tempo de exposição dos acetamidas à zona de maior absorção radicular deve ser de grande importância na atividade desses herbicidas. JORDAN \& HARVEY (1980), constataram que os acetamidas são mais eficientes quando absorvidos pelo sistema radicular.

Uma maior lixiviação, a qual deduz-se ter havido na areia lavada, deve-se ao fato de tratar-se de um substrato eletricamente neutro e de textura mais grossa que os demais substratos constituídos. Efeitos do tamanho das partículas do solo e do conteúdo de água em relação à concentração dos herbicidas metribuzin e simazine, na solução do solo, foram avaliados por HANCE (1976), tendo 
trabalhado com partículas de dois tamanhos (grande $>2,5 \mathrm{~mm}$ e pequena $<0,5 \mathrm{~mm}$ ), secas ao ar com $12 \%$ de água, adicionando-se água uma hora e uma semana após, à razão de 1:1. As análises da solução do solo foram realizadas 1,24 e 48 horas após a adição da água. Para o metribuzin, foi observada uma maior concentração nas soluções extraídas, logo após o molhamento de amostras com diâmetro de partículas $>2,5 \mathrm{~mm}$, entretanto, quando se fizeram avaliações, $\mathbf{4 8}$ horas após as aplicações, as diferenças foram insignificantes. Não se observaram diferenças para o simazine, em relação ao tamanho dos agregados quando estes foram molhados.

A expressiva lixiviação supostamente havida no substrato areia lavada, que resultou em valores elevados de $I_{30}$ para os três parâmetros testados, possui sustentação em REINARHDT \& NEL (1981), tendo esses autores, afirmado que a ocorrência de uma chuva intensa imediatamente após a aplicação de herbicidas derivados da amida, a maior parte desse produtos pode mover-se para baixo da zona de absorção radicular das plântulas, durante a emergência, diminuindo a sua bioatividade.

Outra hipótese aventada para os $\mathbb{I}_{50}$ estimados para os leitos em areia terem sido superiores aos dos demais substratos, pode ser explicada por AUDUS (1986), que preconiza que herbicidas que possuem átomos de nitrogênio $\mathrm{em}$ suas moléculas, quando absorvidos em doses subletais pelas plantas, estimulam a síntese de proteína, reduzindo mais rapidamente o nitrato absorvido pelas plantas. Isto resulta num maior crescimento da planta ou, em acúmulo de proteínas, em prejuizo aos carboidratos solúveis.

\section{CONCLUSÃo}

Os resultados obtidos demonstram que, em solos com texturas tendendo à arenosa, o herbicida Zeta apresenta grande mobilidade vertical, essa constatação é positiva no aspecto de que essa propriedade permite que o produto possa atingir raízes profundas de plantas daninhas e de difícil controle.

Nos solos com alto teor de argila e matéria orgânica os efeitos do herbicida foram, confundidos com os do alumínio tóxico $\left(\mathrm{Al}^{+3}\right)$ na inibição do desenvolvimento da planta, haja visto, que as plantas de sorgo granífero são extremamente susceptíveis a esses cátions trivalentes.
Em linha gerais, o experimento permitiu inferir que quanto maior o teor de argilas ativas $e$ de matéria orgânica presentes no solo, maior a dose do herbicida requerida para um dado controle percentual de plantas daninhas.

\section{REFERENCIAS BIBLIOGRAFICAS}

AHRENS, W.H., ed. Herbicide Handbook. 7.ed. Champaign: Weed Science Society of America, 1994. $352 \mathrm{p}$.

ALMEIDA, F.S.; RODRIGUES, B.N. Guia de herbicidas: recomendaçōes para o uso adequado em plantio direto e convencional. Londrina: IAPAR, 1988. 603p.

ANDERSON, W.P. Weed science principles. New York: West Publishing, 1983. 655p.

AUDUS, L.J. Herbicides: physiology, biochemistry and ecology. New York: Academic Press, 1986. 2v.

BALDWIN, F.L.; SANTELMANN, P.W.; DAVIDSON, J.M. Prometrine movement across and through the soil. Weed Science, v. 43, n. 4, p. 285-8, 1985.

DAO, T.H.; LAVY, T.L. Atrazine adsorption on soils influenced by temperature, moisture content and electrolyte concentrations. Weed Science, v. 46, n. 3, p. 303-8, 1988.

ESHEL, Y. Phytotoxicity, leachability and site of uptake of 2-chlom-2; 6-diethyl-N-methoxymethyl acetanilide. Weed Science, v. 2 , n. 4, p.441-4, 19

HANCE, R.J. The effect of soil aggregate size and water content on herbicide concentration in soil water. Weed Research, v.16, n.5, p.317-21, 1976.

JORDAN, G.L.; HARVEY, R.G. Factors influencing activity of acetanilide herbicides on processing peas (Pisum sativum) and annual weeds. Weed Science, v. 28, n.5, p.589-93, 1980.

MUZILLI, O.; OLIVEIRA, F.L.; CALEGARI, A. A cultura do millho no Paraná manejo do solo. Londrina: Fundação Instituto Agronômico do Paraná, 1991. p.85-121.

OBRIGAWITH, T.; HONS, F.M.; ABERNATHY, J.R.; GIPSON, J.R. Adsorption, desorption and mobility of metolachlor in soils. Weed Science, v. 29, n. 3, p.332-6, 1981 .

PETER. C.J.; WEBER, J.B. Adsorption, mobility, and efficacy of alachlor and metolachlor as influenced by soil properties. Weed Science, v. 33, n. 6, p. 874-81, 1985.

PUTNAN, A.R.; RICE, JUNIOR, R.P. Environmental and edaphic influences on the selectivity of alachlor on snap beans (Phaseolus vulgaris). Weed Science, V.27, N.5, P.570-4, 1979. 
REINARHDT, C.F.; NEL, P.C. The effect of some environment factor on Alachlor activity. Journal of Flant and Soil, v.1, n. 1, p. 7-20, 1981.

SARRIÉS, G.A.; OLIVEIRA, J.C.V.; ALVES, M.C. SANEST. Piracicaba: CIAGRI, 1992. 80p. (Série didática, 6).

SCALLA, R. Les herbicide: mode d'action et principes d'utilisation. Paris: INRA, 1991. 450p.
WEBER, J.B.; MILLER, C.T. Organic chemical movement over and through soil. In: SAWHNEY, B.L.; BROWN, $K$. Reactions and movement of organic chemical in soil. Madison: Soil Science Society of Agronomy, 1989. p. 305-33p.

Recebido para publicação em 17.07.95 Aceito para publicação em 19.08.95 